\title{
Stabilization of Nanoparticles Produced by Hydrogenation of Palladium-N-Heterocyclic Carbene Complexes on the Surface of Graphene and Implications in Catalysis
}

Andrés Mollar-Cuni, ${ }^{\dagger}$ David Ventura-Espinosa, ${ }^{\dagger}$ Santiago Martín, ${ }^{\ddagger}, \S$ Álvaro Mayoral, ${ }^{\|, \perp}$ Pilar Borja, ${ }^{*}, \dagger \odot$ and Jose A. Mata* ${ }^{\dagger}+0$

\author{
${ }^{\dagger}$ Institute of Advanced Materials (INAM), Universitat Jaume I, Avda. Sos Baynat s/n, 12006 Castellón, Spain \\ ${ }^{\ddagger}$ Departamento de Química Física, Facultad de Ciencias, Universidad de Zaragoza, C/Pedro Cerbuna 12, 50009 Zaragoza, Spain \\ ${ }^{\S}$ Instituto de Ciencias de Materiales de Aragón (ICMA), Universidad de Zaragoza-CSIC, 50009 Zaragoza, Spain \\ "Instituto de Nanociencia de Aragón (INA) and Laboratorio de Microscopias Avanzadas (LMA), edificio i+d Campus Río Ebro, \\ Universidad de Zaragoza, C/Mariano Esquillor, s/n, 50009 Zaragoza, Spain
}

\section{Supporting Information}

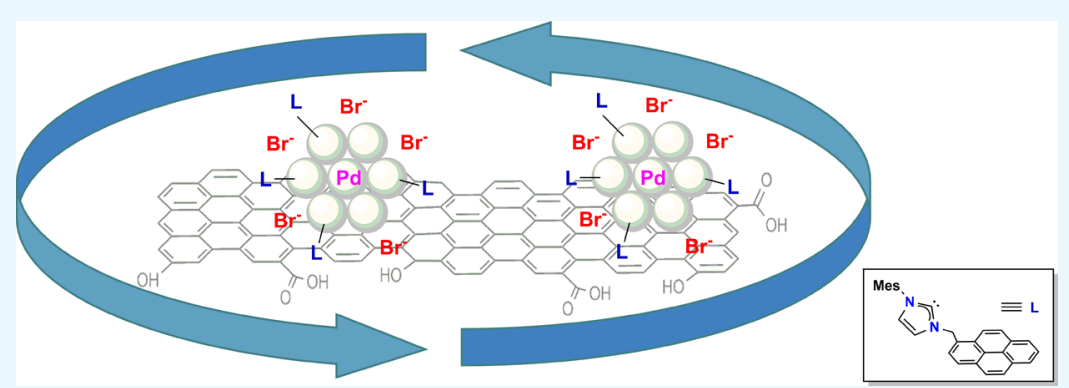

ABSTRACT: Palladium nanoparticles (NPs) have been obtained by decomposition of well-defined palladium complexes noncovalently anchored onto the surface of reduced graphene oxide. Morphological analysis by microscopy showed the presence of small palladium NPs homogeneously distributed on the support. Characterization by X-ray photoelectron spectroscopy confirmed that palladium NPs contain $\mathrm{Pd}(2+)$ and $\operatorname{Pd}(0)$ oxidation states and the presence of $\mathrm{N}$-heterocyclic carbene and bromo ligands. The catalytic properties of the NPs with and without the support have been evaluated in the hydrogenation of alkynes. Supported palladium NPs showed increased activity versus the nonsupported ones and could be recycled up to 10 times without the loss of catalytic activity. The composition of the palladium NPs is different for each catalytic cycle indicating a dynamic process and the formation of different catalytic active species. On the contrary, the unsupported palladium NPs showed limited activity caused by decomposition and could not be recycled. The role of the support has been investigated. The results indicate that the support influences the stability of palladium NPs.

\section{INTRODUCTION}

Palladium plays a major role in the synthesis of value chemicals and pharmaceuticals by carbon-carbon coupling and hydrogenation catalytic reactions. ${ }^{1-9}$ The nature of the catalytic active species is under continuous debate, and different types have been proposed as key intermediates including molecular complexes, clusters, single atoms, and nanoparticles (NPs). ${ }^{10-14}$ Among them, palladium NPs have received an increasing attention because they are observed in many catalytic processes and serve as a class of highly active catalysts. ${ }^{15-18}$ An important limitation in the use of NPs arise from deactivation by sintering or agglomeration. Functionalization of metal NPs with organic ligands avoids aggregation and controls the particle size and distribution. ${ }^{19-21}$ These properties markedly regulate the catalytic applications of metal NPs. However, even the functionalized NPs suffer dynamic changes at the surface during the catalytic reactions, and single atoms and/or metal clusters are released to the reaction media forming new species. ${ }^{22}$ If the generation of the new species is not reversible, the original NPs evolve into the formation of different metal NPs with different catalytic properties. As an alternative, the use of supports is a complementary approach to increase the stability of metal NPs functionalized with organic ligands. ${ }^{23-27}$ The combination of ligands for avoiding particle agglomeration with supports increases the potential catalytic applications of the hybrid catalytic materials, especially in the recycling and reuse of metal NPs.

Palladium NPs functionalized with N-heterocyclic carbene (NHC) ligands show potential applications in catalysis, and ligand-free palladium NPs have been immobilized onto

Received: August 28, 2018

Accepted: October 25, 2018

Published: November 9, 2018 
Scheme 1. Synthesis of Palladium Complex 2, Immobilization onto rGO (2-rGO), and Synthesis of Free Palladium NPs (2NPs) and Supported onto rGO (2-rGO-NPs)
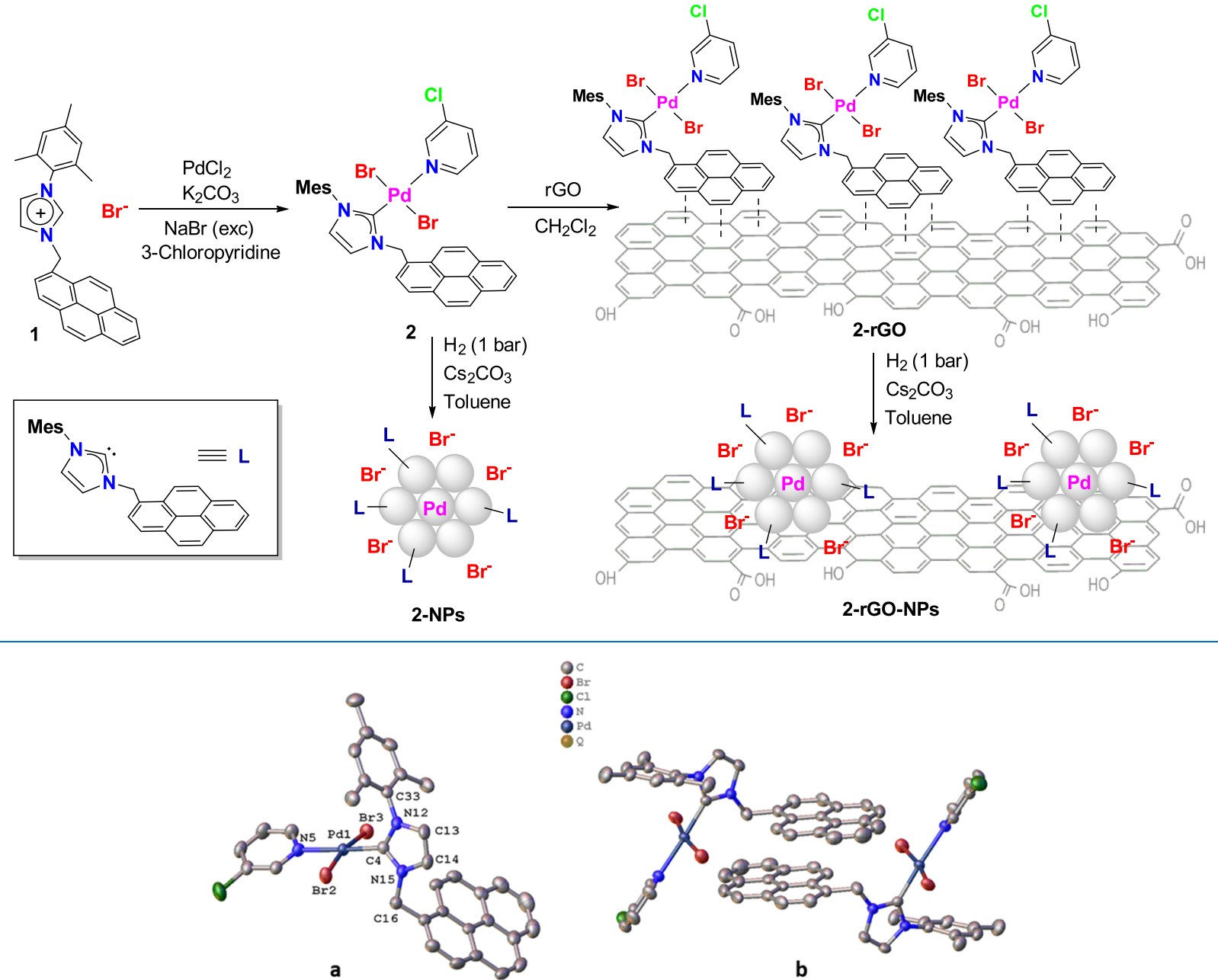

Figure 1. (a) Molecular structure of complex 2 (b) X-ray packing view of 2 showing an interplanar distance between the pyrene tags of $3.5 \AA$.

graphene, but the combination of organic ligands and graphene is unexplored. ${ }^{28,29}$ In this article, we discuss the preparation of palladium NPs (Pd-NPs) containing NHC ligands by the decomposition of well-defined organometallic complexes. ${ }^{30-32}$ The catalytic properties of the Pd-NPs are evaluated in the hydrogenation of alkynes as a benchmark reaction. We describe the influence of graphene as a support for the PdNPs and the potential benefits in catalytic applications. The use of NHC ligands and graphene as a support allows reusing and recycling the palladium NPs. The modular approach, starting from molecular complexes, NPs, and immobilization, allows an in-deep characterization of the materials and offers the opportunity to study the influence of the individual components in the design of hybrid catalytic systems.

\section{RESULTS AND DISCUSSION}

Synthesis, Immobilization, and Characterization of $\mathbf{2}$ and 2-rGO. The palladium complex $\mathbf{2}$ at the molecular level or supported onto reduced graphene oxide (2-rGO) was used for the synthesis of free and supported palladium NPs (Scheme 1). Complex 2 was obtained by the methodology described for the palladium PEPPSI-type complexes. ${ }^{33}$ The imidazolium salt $\mathbf{1}$ was reacted with palladium(II) chloride and potassium carbonate in 3-chloropyridine to afford complex 2 in good yield. An excess of sodium bromide was added to the reaction media to avoid halide scrambling in the final product. Complex 2 was fully characterized by nuclear magnetic resonance (NMR) spectroscopy, ESI-MS spectrometry, elemental analysis, X-ray photoelectron spectroscopy (XPS), UV/vis absorption spectroscopy, and thermogravimetric analysis (TGA). We observed that TGA is a valuable characterization technique for palladium PEPPSI-type complexes because it shows the sequential mass losses assigned to different palladium ligands (Figure S17 in the Supporting Information). The molecular structure of 2 was confirmed by X-ray crsytallography (Figure 1a). The palladium shows a distorted square-planar environment with the $\mathrm{Br}$ ligands in the trans position. The crystal packing reveals that the pyrene tag of different molecules are close in proximity showing $\pi$-staking interactions with an interplanar distance of $3.5 \AA$ (Figure $1 \mathrm{~b}$ ).

The immobilization of complex 2 onto graphene for obtaining the hybrid material 2-rGO was carried out, as previously described. ${ }^{34,35}$ This methodology allows a controlled grafting of molecular complexes on the surface of reduced rGO. The immobilization conditions are mild; therefore, it is expected that the properties of the rGO and the metal complex are preserved. The pyrene tag permits the formation of $\pi$-interactions with graphene that retain the 

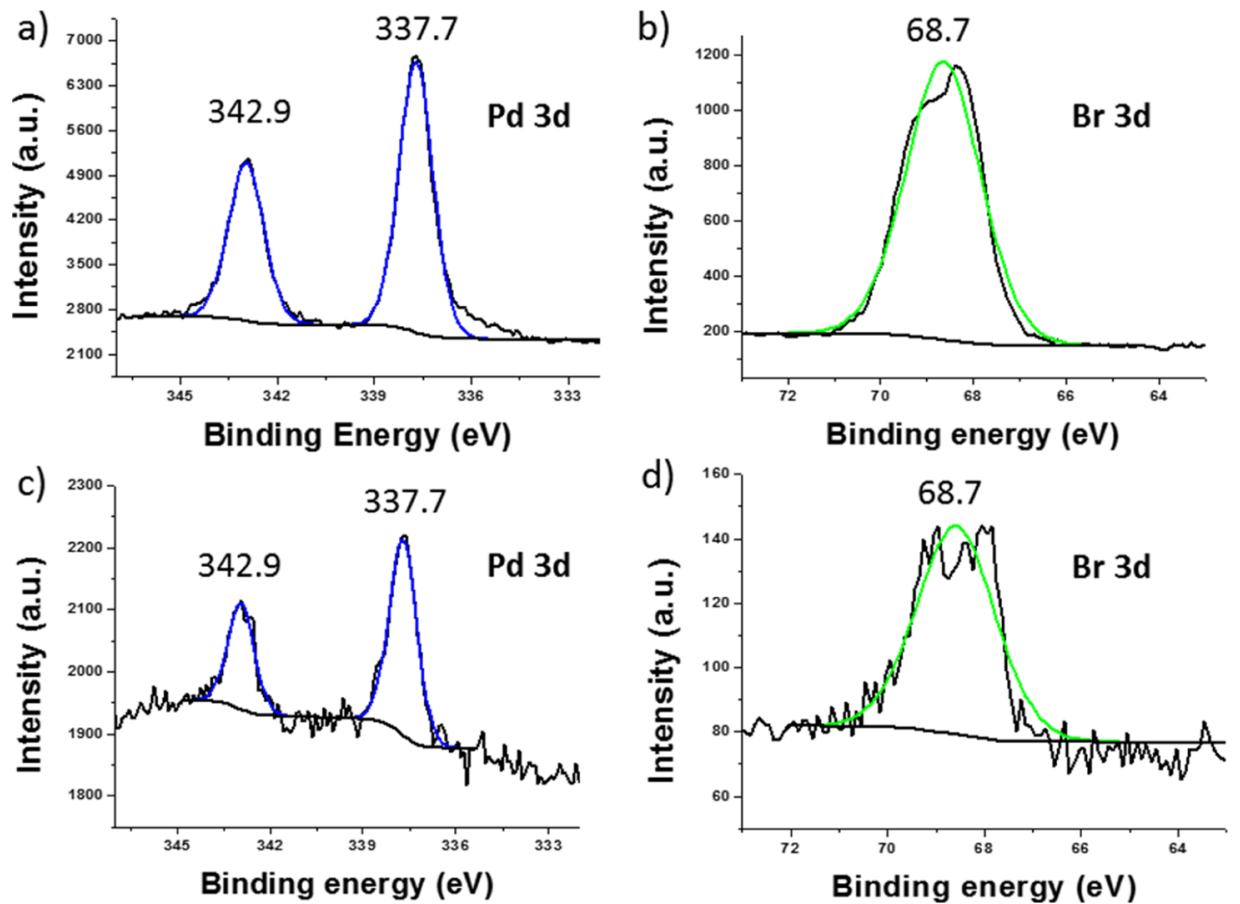

Figure 2. Comparative XPS analysis of the core-level peaks (eV) of Pd 3d and Br 3d for complex 2 (a,b) and hybrid material 2-rGO (c,d). See the Supporting Information for details.

molecular complex attached to the material. The $\pi$-staking interactions are considered weak but their multiplicity, such in the case of graphene, grants the efficient immobilization of molecular complexes. This is evidenced by the formation of short-distance interactions at the molecular level as the ones found in the crystal packing of complex 2 . We have previously observed that ruthenium, iridium, and gold molecular complexes containing a pyrene group form strong $\pi$-staking interactions with rGO. The catalytic properties reveal that these interactions are maintained during the recycling experiments. $^{36-41}$

Characterization of 2-rGO was performed by highresolution transmission electron microscopy (HRTEM), XPS, UV-vis, Raman, and TG, and the exact amount of complex 2 onto graphene was analyzed by inductively coupled plasma mass spectrometry (ICP/MS) analysis (Supporting Information). The result of the ICP/MS analysis accounted for a $5.5 \% \mathrm{w} / \mathrm{w}$ of 2 onto the graphene surface. XPS analysis was used for the characterization of complex 2 and the hybrid material 2-rGO. This technique provides valuable information of elemental composition and oxidation states. XPS analysis of 2 showed the presence of palladium, nitrogen, bromine, and carbon. As expected for the molecular complex, the binding energies of $\mathrm{Pd}$ confirm the +2 oxidation state. A comparative XPS analysis of $\mathbf{2}$ and $\mathbf{2}$-rGO shows the characteristic corelevel peaks of $\mathrm{Pd} 3 \mathrm{~d}, \mathrm{Br} 3 \mathrm{~d}, \mathrm{~N} 1 \mathrm{~s}$, and $\mathrm{Cl} 2 \mathrm{p}$ at the same binding energy for the molecular complex and the hybrid material (Figures 2 and S21). The XPS analysis confirms the immobilization of molecular complex 2 onto the surface of graphene. All of these techniques suggest that properties of the rGO and the palladium complex $\mathbf{2}$ are preserved during the formation of the hybrid material 2-rGO. In addition, we know the exact nature and composition of the palladium species deposited onto the surface of graphene.

Synthesis and Characterization of 2-NPs and 2-rGONPs. We observed a change in color of the solution when exposing the molecular complex 2 to hydrogen under basic conditions. The initial pale yellow solution of $\mathbf{2}$ in toluene darkens in $20 \mathrm{~min}$, and after $3 \mathrm{~h}$, there is a black precipitate (Figure 3). This black precipitate corresponds to the formation

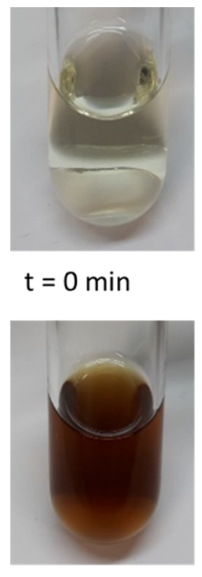

$\mathrm{t}=15 \mathrm{~min}$

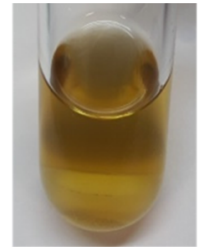

$\mathrm{t}=5 \mathrm{~min}$

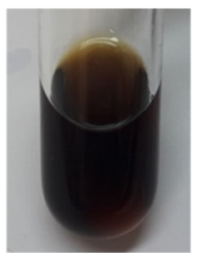

$\mathrm{t}=20 \mathrm{~min}$

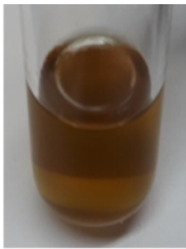

$\mathrm{t}=10 \mathrm{~min}$

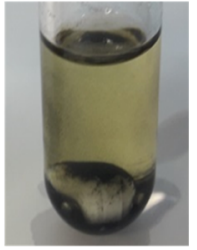

$\mathrm{t}=180 \mathrm{~min}$
Figure 3. Complex 2 evolution under exposure to $\mathrm{H}_{2}$ (1 bar) using toluene in the presence of $\mathrm{Cs}_{2} \mathrm{CO}_{3}$ at $65^{\circ} \mathrm{C}$.

of palladium NPs (2-NPs). Decomposition of the palladium complex $\left[\mathrm{Pd}(\mathrm{NHC})(\mathrm{Br})_{2}(\mathrm{Cl}-\mathrm{Py})\right]$ leads to the formation of palladium NPs containing NHC ligands from an organometallic approach. ${ }^{42-47}$ The presence of ligands avoids aggregation and controls the size of the NPs. HRTEM images confirmed the presence of small palladium NPs with a worm shape (Figure 4a). The XPS analysis reveals the presence of palladium, carbon, nitrogen, and bromine but not of chlorine. The 3-chloropyridine ligand is lost during the NP formation. This ligand is labile., Uncoordination of the metal center is usually observed in Pd-PEPPSI catalytic reactions. High- 

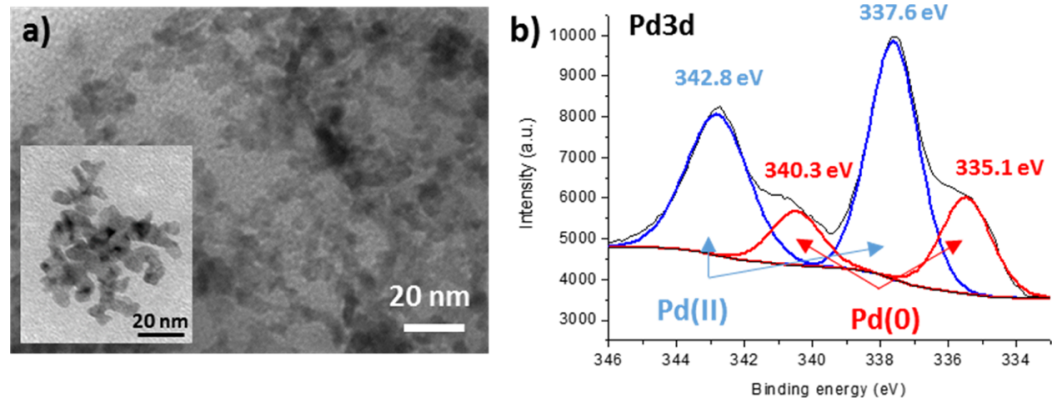

Figure 4. HRTEM image of 2-NPs (a) and XPS analysis (b) showing the presence of $\operatorname{Pd}(0)$ and $\operatorname{Pd}(2+)$.
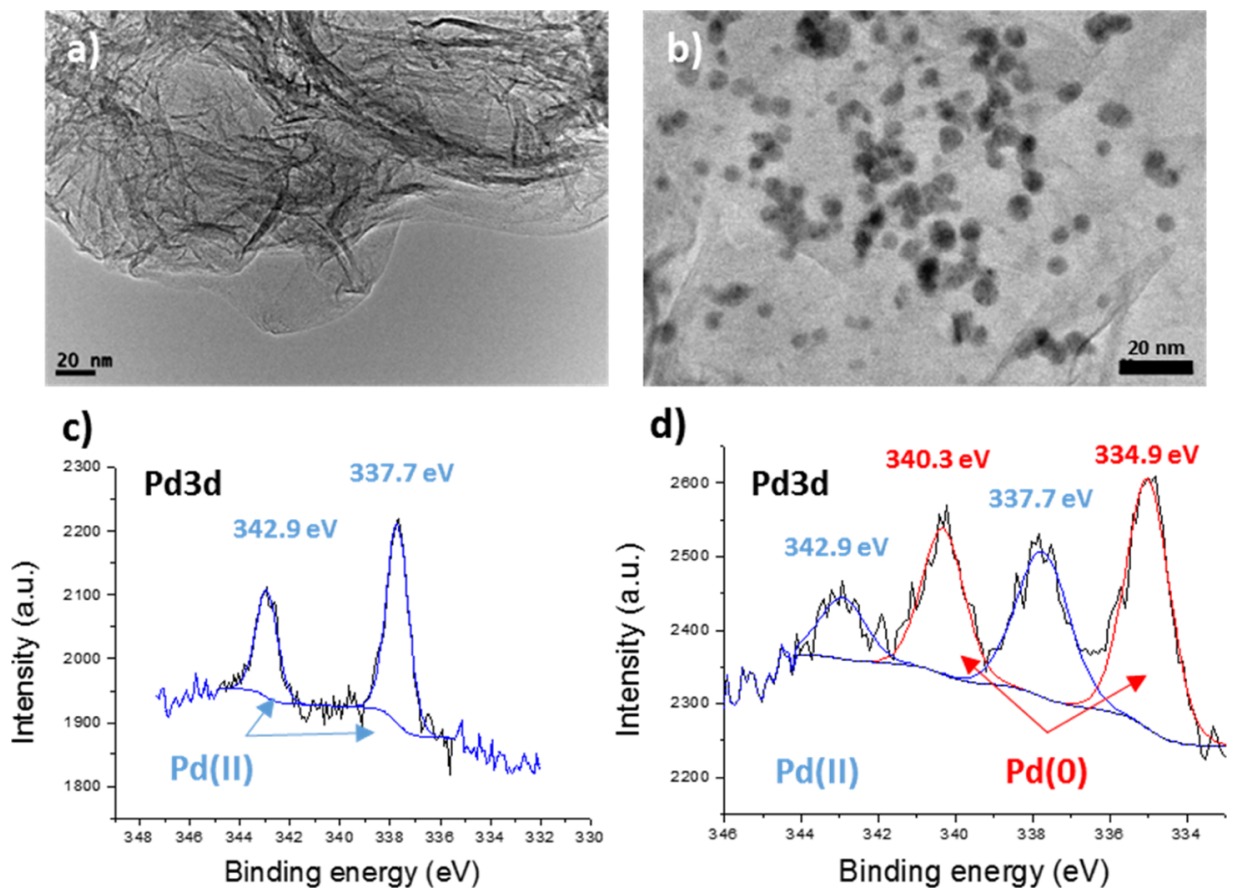

Figure 5. HRTEM images (top) and XPS analysis (bottom) for the core-level peaks of Pd 3d. HRTEM of 2-rGO (a) before and (b) after the exposure to $\mathrm{H}_{2}$. XPS analysis of 2-rGO (c) before and (d) after the exposure to $\mathrm{H}_{2}$ showing the characteristic peaks of $\mathrm{Pd}(0)$ and $\mathrm{Pd}(2+)$.

resolution XPS analysis shows the presence of two doublets for the core-level peaks of $\mathrm{Pd} 3 \mathrm{~d}$, indicating the presence of $\operatorname{Pd}(0)$ and $\mathrm{Pd}(2+)$ oxidation states (Figure $4 \mathrm{~b}$ ). The results showed that 2-NPs contain palladium atoms in two oxidation states, $\mathrm{NHC}$ and $\mathrm{Br}$ ligands. NHC ligands have previously been used to avoid aggregation in palladium NPs. ${ }^{48-52}$

The hybrid material 2-rGO was exposed under the same conditions as the molecular complex 2 for the formation of palladium NPs. HRTEM images of the hybrid material 2-rGO before the exposure to hydrogen showed the single-layer nature of graphene and the absence of palladium NPs (Figure 5a). The EDS elemental mapping confirms the elemental composition of the molecular complex $2(\mathrm{Pd}, \mathrm{N}, \mathrm{Br}$, and $\mathrm{Cl})$ and the homogeneous distribution of the complex over all of the graphene surface (Figures S23 and S24). On the contrary, HRTEM images of the hybrid material 2-rGO after the exposure to hydrogen showed the formation of palladium NPs of an average size of $4 \mathrm{~nm}$ and spherical shape (Figure $5 \mathrm{~b}$ ). The presence of rGO influences the shape of the palladium NPs from worm shape to spherical shape. XPS analysis before the exposure to hydrogen confirmed the presence of only $\operatorname{Pd}(2+)$ species in the 2-rGO hybrid material (Figure 5c). After the exposure to $\mathrm{H}_{2}$, XPS analysis confirms the presence of palladium, nitrogen, bromine, carbon, and oxygen. More interesting is the formation of $\operatorname{Pd}(0)$ oxidation state that coexists with $\mathrm{Pd}(2+)$ as in 2-NPs (Figure $5 \mathrm{~d}$ ). These results suggest that exposing 2-rGO to hydrogen under basic conditions produce palladium NPs of $\mathrm{Pd}(2+)$ and $\operatorname{Pd}(0)$ that contain NHC and bromo ligands immobilized onto graphene. The average size of the palladium NPs are slightly smaller compared to the particles formed using the molecular complex 2. Graphene acts as a support for the production of small and well-dispersed palladium NPs. We have observed that graphene acts as an NP sponge in the in situ formation of gold particles by laser ablation. The results revealed a control of the particle size, and the gold NPs obtained in the presence of graphene were smaller. ${ }^{53}$ This process is general, and many reports confirm the immobilization of metal NPs on the surface of graphene by interactions of the d-metal orbitals with the $\pi$-delocalized electronic density of the graphene material. ${ }^{29,54,55}$

Catalytic Studies. The catalytic hydrogenation of alkynes was evaluated using molecular hydrogen at low pressure with the precatalysts molecular complex $\mathbf{2}$ and the hybrid material 2-rGO. The catalytic active palladium NPs (2-NPs and 2rGO-NPs) were generated in situ under appropriate reaction 
conditions. In a general procedure, a Schlenk flask was charged with the catalyst, base, alkyne, and solvent. Then, a balloon of $\mathrm{H}_{2}$ ( $\sim 1$ bar) was connected to the system, and the reaction was immersed in a preheated oil bath. The monitoring of the reaction and the product distribution were analyzed by GC chromatography and ${ }^{1} \mathrm{H}$ NMR using anisole as an internal standard. The hydrogenation reaction is general and works for different bases and solvents. Control experiments using only rGO reveal that palladium species are active catalysts. After optimization using diphenylacetylene as a model substrate, the best reaction conditions in terms of activity and selectivity are catalytic amounts of $\mathrm{Cs}_{2} \mathrm{CO}_{3}$, dry toluene, and $65{ }^{\circ} \mathrm{C}$.

Reaction monitoring profile in the hydrogenation of 1 phenyl-1-butyne with precatalyst $2(1 \mathrm{~mol} \%)$ showed an induction period of $15 \mathrm{~min}$, indicating the formation of the catalytic active species 2-NPs (Figure 6a). Then, the alkyne was hydrogenated to the $Z$-alkene in excellent yield and with good stereoselectivity $(t=1.5 \mathrm{~h}$, alkyne conversion $=97 \%$, alkenes yield: $92 \%$, ratio $Z / E=95: 5$, and alkane yield $5 \%$ ). Catalyst 2-NPs is highly stereoselective for the cis isomer even at high alkyne conversion. When the alkyne was consumed, the

a) - - $\%$ alkyne $\longrightarrow$ - $\%$ Z-alkene $\longrightarrow$ E-alkene $\longrightarrow$ - $-\%$ alkane

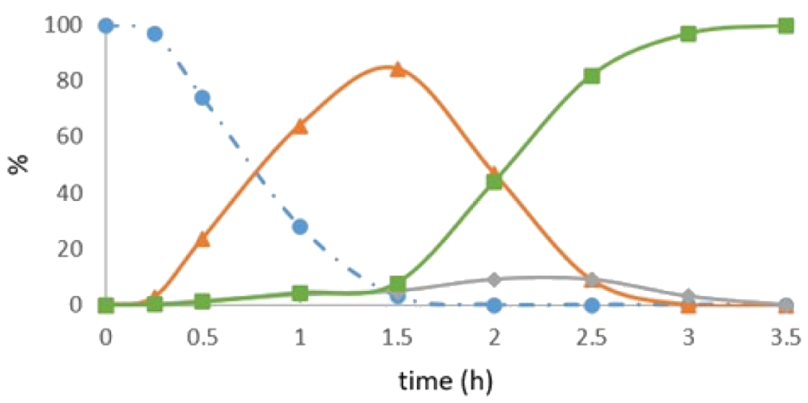

b) - e- \% alkyne $\longrightarrow$ - $\%$ Z-alkene $\longrightarrow$ - - E-alkene - - $\%$ alkane

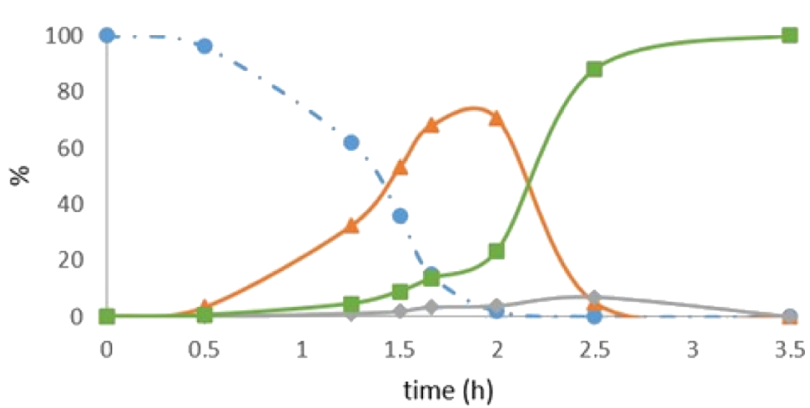

c)

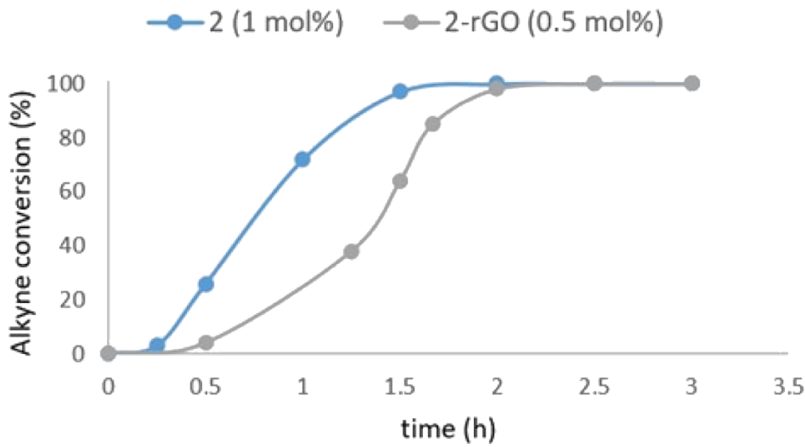

Figure 6. Hydrogenation of 1-phenyl-1-butyne with precatalysts (a) 2 (1 mol \%), (b) 2-rGO (0.5 mol \%), and (c) comparison of alkyne conversion for both precatalyst.
$E$ and $Z$ alkenes were hydrogenated to the corresponding alkane. As the hydrogenation process was sequential, the formation of alkanes could be avoided by stopping the reaction at convenient time. Selective palladium catalysts in the semihydrogenation of alkynes are scarce, and over-reduction is better controlled by transfer hydrogenation methodologies. ${ }^{56-60}$ The reaction monitoring using precatalyst 2-rGO showed an identical profile to catalyst 2-NPs but with a longer induction period $(30 \mathrm{~min}$ ) (Figure $6 \mathrm{~b}$ ). Comparison of the catalytic activity of 2-NPs versus 2-rGO-NPs revealed that the reaction using catalyst 2-rGO-NPs started later because of a longer induction period but then proceeded at higher rates. This result is significantly different if we consider that catalyst 2-rGO-NPs contains half amount of palladium compared to 2NPs (Figure 6c). When the reaction was carried out at the same catalyst loading $(0.5 \mathrm{~mol} \%)$, full conversion of alkyne was not observed using 2-NPs, indicating catalyst deactivation. These results show that immobilization of molecular complexes onto graphene lead to a more efficient catalysts, and that the kinetics are not affected by diffusion problems.

The nature of the catalytic active species was further analyzed by poisoning experiments using poly(4-vinylpyridine) (P4VP) as a scavenger of $\mathrm{Pd}(\mathrm{II})$ molecular species and the $\mathrm{Hg}$ drop test as an scavenger of Pd NPs (Figure S27). ${ }^{61-66}$ The reactions were performed using precatalyst $2(1.0 \mathrm{~mol} \%)$ and 1-phenyl-1-butyne as the substrate. The results showed that in the presence of $\mathrm{P} 4 \mathrm{VP}$, the hydrogenation rate is affected but not inhibited and after the addition of $\mathrm{Hg}$, the reaction immediately stopped. Partial poisoning experiments suggest that the catalytic active palladium species are heterogeneous in nature and confirm that the active catalytic species are 2-NPs and 2-rGO-NPs. Then, we performed a Maitlis hot filtration test to support preliminary data in the formation of NPs. ${ }^{67}$ In the hydrogenation of 1-phenyl-1-pentyne with precatalyst 2, after $1 \mathrm{~h}$ reaction (GC conversion $40 \%$ ), half of the reaction mixture was filtered off through celite at $65^{\circ} \mathrm{C}$. The filtrate was maintained for $5 \mathrm{~h}$ under identical conditions, but the GC analysis indicated that no further hydrogenation occurred (GC conversion $40 \%$ ). On the contrary, the remaining mixture achieved full conversion in $2 \mathrm{~h}$ reaction. This experiment reinforces the heterogeneous nature of the catalytic active species.

An interesting topic to address in supported catalysis is the influence of the support. The support may only act as a medium that holds the active catalyst or may also play a role during the catalytic reaction facilitating the conversion of reagents into products. ${ }^{68-71} \mathrm{We}$ explored the influence of the rGO support on palladium NPs during hydrogenation. The experiment consisted of the monitoring of the reaction profile in the hydrogenation of 1-phenyl-1-butyne with precatalyst 2, the hybrid material 2-rGO, and a mixture of molecular complex 2 with rGO for simulating the material 2-rGO (Figure 7 ). In all cases, we observed an induction period corresponding to the formation of NPs. The results revealed that precatalyst 2 did not afford full conversion, and the reaction was stopped after $15.5 \mathrm{~h}$. There is catalyst deactivation because of a lack of stability of 2-NPs under the reaction conditions. In the case of the hybrid material 2-rGO, full conversion of alkyne was achieved in $2.3 \mathrm{~h}$ indicating again that $\mathrm{rGO}$ plays a role in the stabilization of 2-NPs. More interesting results were obtained by the mixture of catalyst 2 with rGO. The catalytic activity of the mixture is as high as the hybrid material 2-rGO. The catalytic properties of complex 2 significantly increased after 


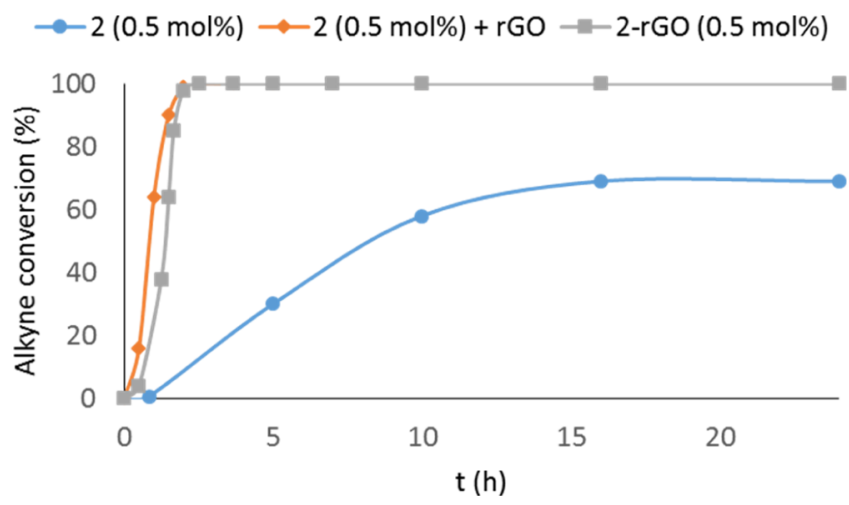

Figure 7. Hydrogenation of 1-phenyl-1-butyne with precatalyst 2 (blue circles), 2-rGO (grey squares), and $\mathbf{2}+$ free rGO $(20 \mathrm{mg}$ ) (orange diamonds). Catalyst loading of $0.5 \mathrm{~mol} \%$ based on palladium. $\mathrm{H}_{2}$ pressure of $1 \mathrm{bar}, \mathrm{Cs}_{2} \mathrm{CO}_{3}(10 \mathrm{~mol} \%)$ in toluene at $65{ }^{\circ} \mathrm{C}$.

the addition of rGO. These results support that the graphene plays an important role during the catalytic experiment in the stabilization of palladium NPs and avoids deactivation.

Precatalysts $\mathbf{2}$ and 2-rGO are active in the hydrogenation of different substrates at low hydrogen pressure and short reaction times (Table 1 ). Internal alkynes were rapidly semihydrogenated to the corresponding alkenes with good to excellent stereoselectivity toward the $Z$ isomer (Table 1, entries 1-8). We have not observed isomerization or migration of the $Z$-alkenes. Prolonged reaction time produced the hydrogenation of the alkenes to the corresponding alkanes. The complete reaction monitoring profiles are in the Supporting Information (Figures S29-S40). The reactions are sequential and can be stopped at the appropriate time in the formation of alkene or alkane. Terminal alkynes react equally well but tend to give lower chemoselectivity at high conversions (Table 1, entries 9-12). We noted that by performing hydrogenations using $0.5 \mathrm{~mol} \%$ of catalyst 2 , the reaction stopped at ca. $50 \%$. On the contrary, using $0.5 \mathrm{~mol} \%$ of catalyst 2-rGO affords quantitative yields in short reaction times. As we have previously observed, the immobilization of precatalyst 2 onto graphene plays a role in the catalytic process. The graphene does not act as a mere support. The immobilization of palladium complexes onto graphene helps in the stabilization of the catalytic active species and allows the reduction of catalyst loading.

We performed competitive experiments to further evaluate the selectivity properties of precatalysts 2 and 2-rGO. The competitive studies were carried out monitoring the hydrogenation reaction of alkynes in the presence of substrates containing ketone, nitrile, and nitro groups. In the alkyne/ ketone experiment, 1-phenyl-1-butyne was mixed with acetophenone in equimolar amounts. Reaction monitoring using precatalysts $\mathbf{2}$ and $\mathbf{2}$-rGO showed a complete conversion of alkyne without ketone hydrogenation. Similar results were obtained in the case of alkyne/nitrile experiment using benzonitrile as a substrate. Competition experiments show that hydrogenation of alkynes tolerates the presence of nitriles and ketones (Figure S28). Different results were obtained using the molecular complex $\mathbf{2}$ or the supported $\mathbf{2 - r G O}$ in the competitive experiment alkyne/nitrobenzene. The hydrogenation reaction of 1-phenyl-1-butyne in the presence of nitrobenzene using precatalyst 2 was completely unselective. After $2 \mathrm{~h}$ reaction, the presence of aniline was already observed, and the alkyne was not completely hydrogenated even after $20 \mathrm{~h}$ reaction. On the contrary, for the same experiment but using precatalyst 2-rGO, we observed complete alkyne hydrogenation after $3 \mathrm{~h}$ reaction. The nitrobenzene was not hydrogenated and remained constant after $20 \mathrm{~h}$ reaction (Figure 8). These results suggest that the active catalytic species are different in nature for $\mathbf{2}$ or $\mathbf{2}$-rGO.

Recycling. The main advantage of immobilization of 2 onto the surface of graphene is to recover and reuse the catalyst in multiple runs. Catalyst stability and recycling properties of the hybrid material 2-rGO $(0.5 \mathrm{~mol} \%)$ were

\section{Table 1. Hydrogenation Substrate Scope}

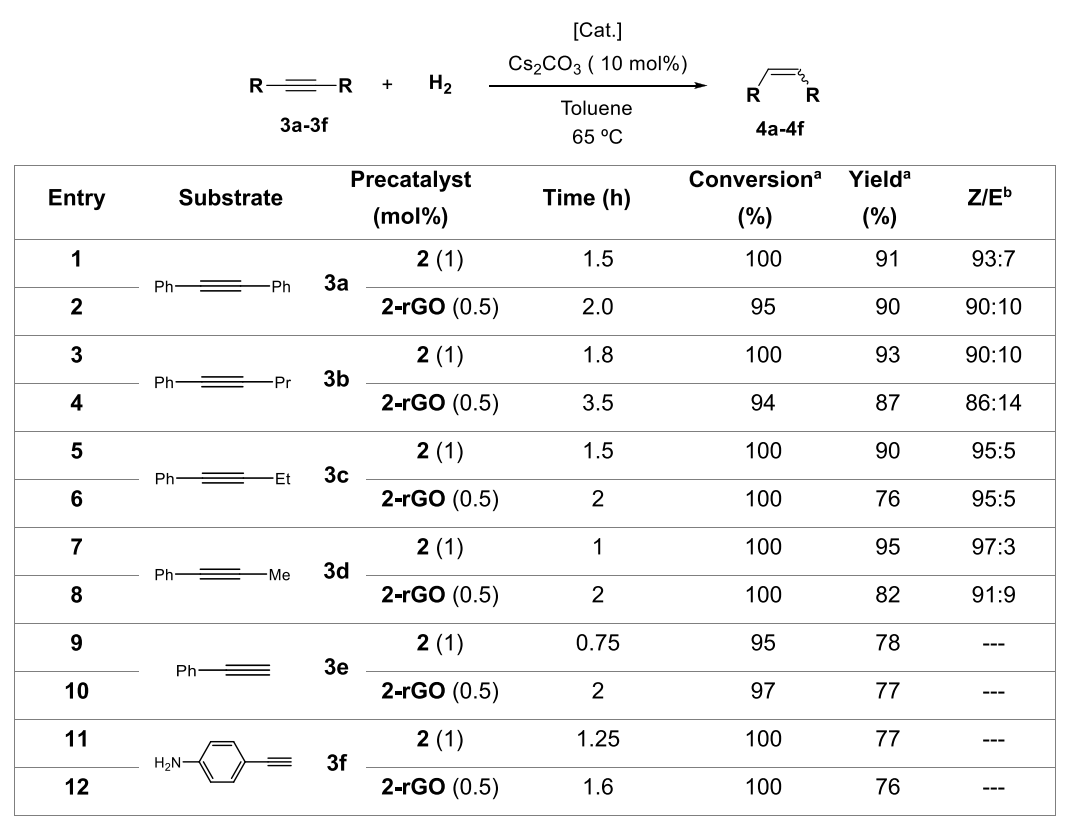

${ }^{a}$ Conversions and yields determined by GC. Yields calculated by the sum of alkenes. ${ }^{b}$ Product distribution determined by ${ }^{1} \mathrm{H}$ NMR. 
a)

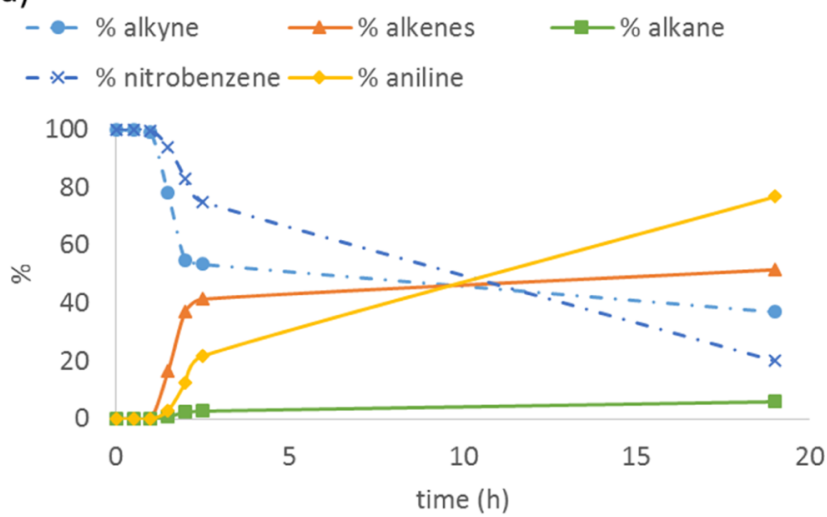

b)

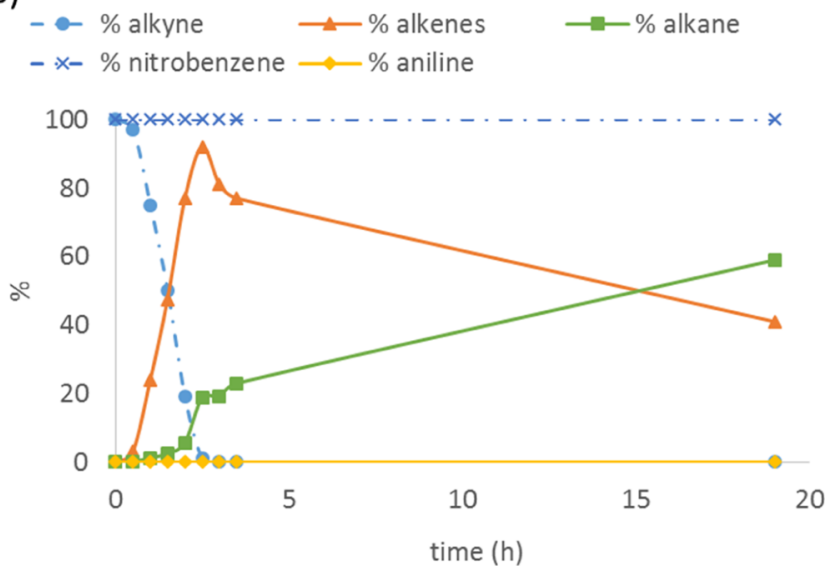

Figure 8. Competitive experiment in the hydrogenation of 1-phenyl1-butyne in the presence equimolar amount of nitrobenzene using (a) $2(1 \mathrm{~mol} \%)$ and (b) 2-rGO (0.5 mol \%). Nitrobenzene is not hydrogenated when using precatalyst 2-rGO.

tested using 1-phenyl-1-butyne as the substrate, dry toluene as the solvent $(2 \mathrm{~mL}), \mathrm{Cs}_{2} \mathrm{CO}_{3}$ as the base $(10 \mathrm{~mol} \%)$, and $\mathrm{H}_{2}(1$ bar) and anisole as the internal standard. In the first run, we observed an induction period of $30 \mathrm{~min}$, and the reaction was stopped after $1 \mathrm{~h}$ and was analyzed by GC. At this point, we observed $91 \%$ of alkyne conversion, $86 \%$ alkene yield with good selectivity toward $Z$-alkene $(Z / E, 90: 10)$, and low overreduction (9\%). The solid precatalyst 2 -rGO that is converted into the catalytic active species 2-rGO-NPs during the induction period was removed from the solution by decantation washed with toluene and reused with the addition of fresh substrate, solvent, $\mathrm{H}_{2}$ and anisole. In the next runs, we did not observe an induction period and the reaction was stopped after $1 \mathrm{~h}$. The catalytic active species are formed in the first run and are stabilized by the support. In the absence of the graphene support (precatalyst 2), the catalytic active species are not stabilized, and the catalytic system could not be recycled. The hybrid material 2-rGO was reused up to 10 times without observing a decrease in activity (Figure 9a). The palladium amount in the filtrate for each run was analyzed by ICP/MS. The results revealed no significant palladium content, indicating the absence of palladium leaching. This result was confirmed by analyzing the palladium content in 2-rGO after the 10th run. Digestion of the solid catalyst and ICP/MS analysis revealed that only $10 \mathrm{wt} \%$ of the initial palladium amount is lost by leaching during the 10 recycling experiments. The stereoselectivity toward the $Z$-isomer and the over- reduction alkane product are maintained constant for each run within the experimental error. These results show that immobilization of $\mathbf{2}$ onto graphene leads to a robust catalytic hybrid material that is highly recyclable.

To rationalize the formation and evolution of palladium active species, we analyzed the nature of the hybrid material 2rGO in the recycling experiment. A small sample of the solid catalyst was taken after selected runs and was analyzed by HRTEM and XPS (Figure 9). HRTEM images confirmed the presence of palladium NPs in all catalytic runs. In the first run, the particle size histogram shows a narrow distribution, and the average size of the Pd NPs is $3.54 \pm 1.03 \mathrm{~nm}(n=236)$ (Figure 9d). After 10 runs, the histogram shows a broader particle size distribution and a slight increase in the size of $\mathrm{Pd}$ NPs (Figure 9i). The average size of Pd NPs after 10 catalytic runs is $6.62 \pm 2.80 \mathrm{~nm}(n=282)$. These observations suggest that Pd NPs suffer slight changes under subsequent catalytic reactions. XPS analysis confirmed that the palladium NPs are composed of $\operatorname{Pd}(2+)$ and $\operatorname{Pd}(0)$ oxidation states. These palladium NPs are decorated by the presence of $\mathrm{NHC}$ and $\mathrm{Br}^{-}$ ligands on the surface. ${ }^{72-76}$ XPS analysis confirms the presence of these ligands by the assignment of peaks corresponding to the $\mathrm{N}(400.6 \mathrm{eV})$ and the $\mathrm{Br}(68.6 \mathrm{eV})$. We have observed that the $\mathrm{Pd}(2+) / \mathrm{Pd}(0)$ ratio is not constant for all of the recycling runs, indicating that both size and composition of the Pd-NPs vary during the catalytic experiment. The amount of $\operatorname{Pd}(2+)$ decreases from run 1 to run 10, meanwhile the amount of $\operatorname{Pd}(0)$ increases. These results suggest that Pd-NPs contain $\operatorname{Pd}(2+)$ at the surface and $\operatorname{Pd}(0)$ at the core. An increase of the size of the NPs produces a decrease of the specific area and consequently decreases the amount of $\mathrm{Pd}(2+)$. This increase of the size of Pd-NPs is also observed in the size histograms built by analyzing 236 and 282 NPs for run 1 and run 10, respectively (Figure 9d,i). The size and composition of Pd-NPs vary under catalytic conditions showing a dynamic exchange and in consequence a different ratio of $\mathrm{Pd}(2+) / \mathrm{Pd}(0)$ oxidation states. There are precedents of dynamic exchange of metal NPs caused by catalytic transformations. ${ }^{77-81}$

Palladium NPs were further characterized by spherical aberration $\left(C_{\mathrm{s}}\right)$-corrected scanning TEM (STEM), using a high-angle annular dark field (HAADF) detector. This mode is highly advantageous over conventional TEM as the contrast is dependent on the atomic number of the elements; therefore, heavier atoms will appear much brighter in the images, helping to visualize the metallic species. Samples corresponding to runs 1 and 10 were selected for the evaluation of their morphology and to characterize the evolution of the palladium NPs during the catalytic experiments. The $C_{\mathrm{s}}$-corrected STEM data showed the presence of small crystalline palladium NPs (Figure 10). Pd units were found in the form of icosahedral (Ih) or fcc NPs in runs $1-10 . .^{82-84}$ In addition to these entities, bright spots were identified all over the carbon support, which corresponded to cesium in the form of individual atoms (Figure S26). We have not observed the formation of other catalytic active species such as single palladium atoms or clusters. The Pd-NPs immobilized on the surface of rGO maintained the original crystalline form after the catalytic experiments. The supports provide a stabilizing effect and allow recycling and reusing the catalytic active species. 

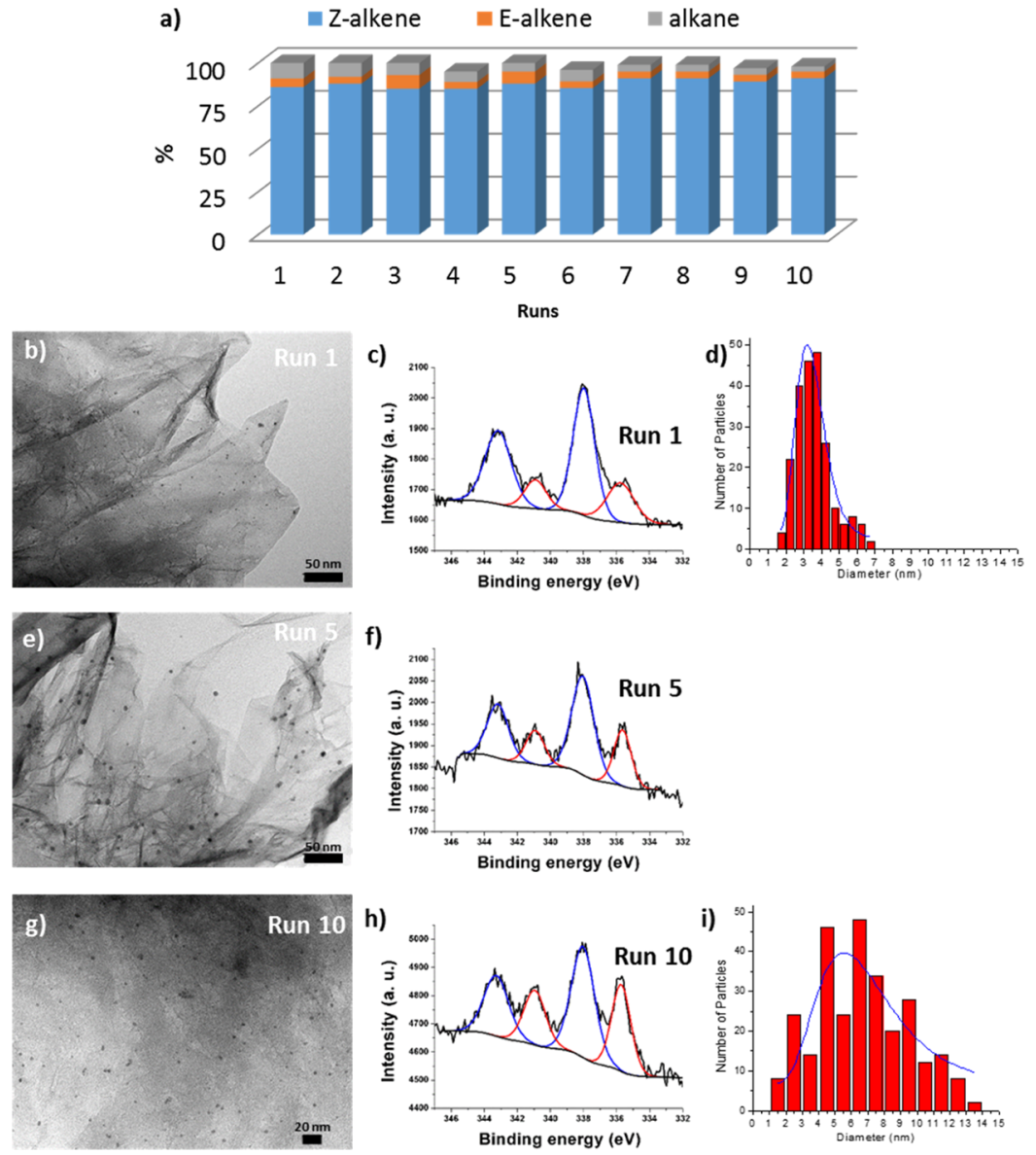

Figure 9. (a) Recycling of 2-rGO ( $0.5 \mathrm{~mol} \%)$ in the hydrogenation of 1-phenyl-1-butyne with molecular $\mathrm{H}_{2}$. First run at $1.5 \mathrm{~h}$ because of the induction time and next runs at $1 \mathrm{~h}$. HRTEM image after run 1 (b), run $5(\mathrm{e})$, and run $10(\mathrm{~g})$ and the corresponding XPS spectra of runs 1 (c), 5 (f), and 10 (h). Blue line corresponds to the $\mathrm{Pd}(\mathrm{II})$ core-level peaks $3 \mathrm{~d}$ and red line corresponds to the core-level peaks $3 \mathrm{~d}$ of $\mathrm{Pd}(0)$. Particle size distribution histograms for run 1 (d) and run 10 (i).
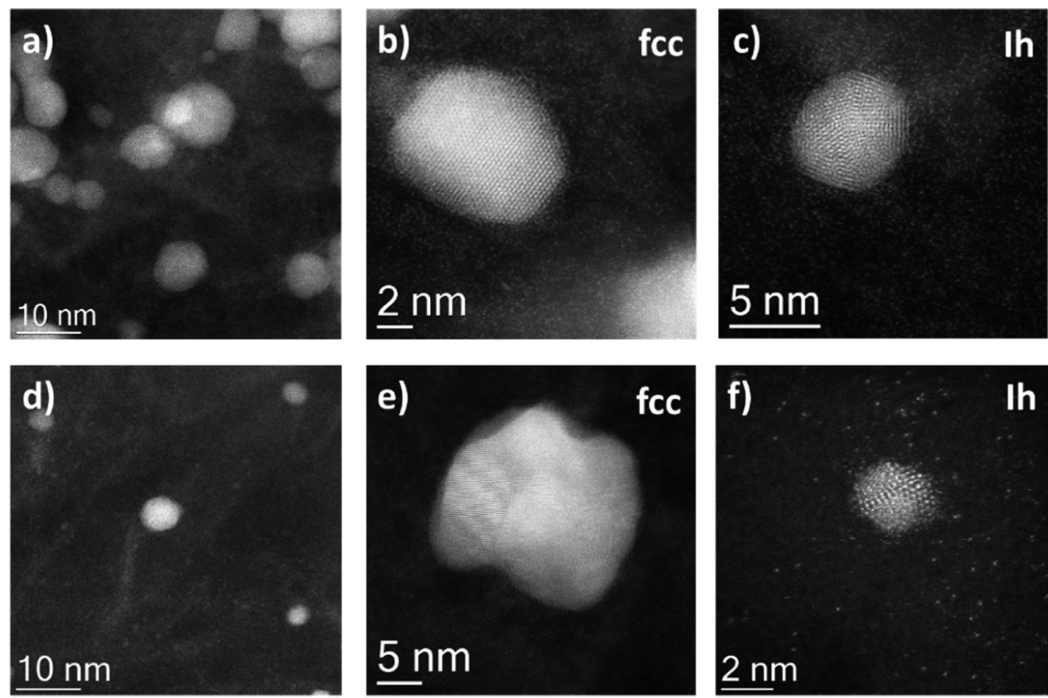

Figure 10. $C_{s}$-corrected STEM-HAADF images of 2-rGO after one catalytic cycle $(a-c)$ and 10 catalytic cycles $(d-f)$. Zooming of the Pd(0) NPs show the fcc crystal nature of some of the NPs (b,e) and the icosahedral (Ih) structures (c,f).

\section{CONCLUSIONS}

Palladium NPs (Pd-NPs) supported on the surface of rGO have been synthesized by decomposition of well-defined organometallic palladium complexes. NHC ligands avoid particle agglomeration by coordination to the surface. XPS analysis reveals that Pd-NPs contain palladium in two oxidation states $[\mathrm{Pd}(2+)$ and $\operatorname{Pd}(0)]$ and confirm the presence of the ligands ( $\mathrm{NHC}$ and $\mathrm{Br}$ ). For comparative purposes, PdNPs without the support were synthesized starting from the 
same organometallic complexes. Characterization by XPS analysis shows similar composition for these NPs in terms of ligands and palladium oxidation states. The catalytic properties in the hydrogenation of alkynes have been evaluated using the free and supported palladium NPs. The results clearly indicate that immobilization of palladium NPs onto rGO improves the catalytic properties in terms of activity and selectivity. The palladium NPs composition shows a dynamic process during the recycling experiments, and different amounts of $\mathrm{Pd}(2+)$ and $\operatorname{Pd}(0)$ oxidation states were observed. The support plays a role in the catalytic performance by the stabilization of palladium NPs.

\section{EXPERIMENTAL SECTION}

Experimental Details. Imidazolium salt 1 was obtained as described. ${ }^{40}$ Solvents were dried using a solvent purification system. NMR spectra were recorded on Bruker spectrometers operating at 300 or $400 \mathrm{MHz}\left({ }^{1} \mathrm{H} \mathrm{NMR}\right)$ and 75 or $100 \mathrm{MHz}$ $\left({ }^{13} \mathrm{C}\left\{{ }^{1} \mathrm{H}\right\}\right.$ NMR), respectively, and referenced to $\mathrm{SiMe}_{4}(\delta$ in ppm and $J$ in Hertz). High-resolution images of TEM HRTEM and HAADF-STEM images of the samples were obtained using a Jem-2100 LaB6 (JEOL) transmission electron microscope coupled with an iNCA Energy TEM 200 (Oxford) energy-dispersive X-ray spectrometer operating at $200 \mathrm{kV}$. Samples were prepared by drying a droplet of $\mathrm{MeOH}$ dispersion on a carbon-coated copper grid. X-ray photoelectron spectra were acquired on a Kratos AXIS ultra DLD spectrometer with a monochromatic $\mathrm{Al} \mathrm{K} \alpha$ X-ray source $(1486.6 \mathrm{eV})$ using a pass energy of $20 \mathrm{eV}$. To provide a precise energy calibration, the XPS binding energies were referenced to the $\mathrm{C} 1 \mathrm{~s}$ peak at $284.6 \mathrm{eV}$. TGA was performed using a TGSTDA Mettler Toledo model TGA/SDTA851e/LF/1600 coupled to a mass spectrometer quadrupole PFEIFFER VACUUM model OmniStar GSD 320 O3, 1-300 uma bearing a tungsten filament. Spherical aberration-corrected $\left(C_{\mathrm{s}}\right.$-corrected) STEM coupled with a HAADF detector measurements were performed in a XFEG Titan Low base FEI $300-60 \mathrm{kV}$ operating at $300 \mathrm{kV}$. The column was fitted with a CEOS aberration corrector for the electron probe, assuring a point resolution of $0.8 \AA$ for the current accelerating voltage. For spectroscopic analyses, the microscope was also equipped with an EDAX EDS detector and a Gatan Tridiem Energy Filter. Prior observations of the sample were dispersed in ethanol and placed onto a holey carbon copper microgrids.

Synthesis of 2. A Schlenk flask was charged with a mixture of imidazolium salt 1 (400 mg, $0.830 \mathrm{mmol})$, palladium(II) chloride (134 mg, $0.750 \mathrm{mmol})$, potassium carbonate $(521 \mathrm{mg}$, $3.77 \mathrm{mmol})$, sodium bromide $(710 \mathrm{mg}, 7.5 \mathrm{mmol})$, and 3chloropyridine $(4 \mathrm{~mL})$ under a nitrogen atmosphere. The resulting suspension was stirred for $19 \mathrm{~h}$ at $80^{\circ} \mathrm{C}$. The reaction mixture was diluted with $\mathrm{CH}_{2} \mathrm{Cl}_{2}$ and filtered through silica and celite. The resulting yellow solution was evaporated to dryness. Complex 2 was precipitated with $\mathrm{CH}_{2} \mathrm{Cl}_{2} /$ hexanes, filtered, and dried. (Yield $400 \mathrm{mg}, 68 \%) .{ }^{1} \mathrm{H}$ NMR (400 MHz, $\left.\mathrm{CDCl}_{3}\right): 8.95\left(\mathrm{~s}, 1 \mathrm{H}, \mathrm{H}_{\text {py27 }}\right), 8.84\left(\mathrm{~d}, 1 \mathrm{H},{ }^{3} J_{\mathrm{Hpy} 31-\mathrm{Hpy} 30}=5.3\right.$ $\left.\mathrm{Hz}, \mathrm{H}_{\mathrm{py} 31}\right), 8.64\left(\mathrm{~d}, 1 \mathrm{H},{ }^{3} J_{\mathrm{Hpyr} 6-\mathrm{Hpyr}}=9.2 \mathrm{~Hz}, \mathrm{H}_{\text {pyr6 }}\right), 8.31-$ $8.17\left(\mathrm{~m}, 5 \mathrm{H}, \mathrm{H}_{\text {pyr }}\right), 8.12\left(\mathrm{AB}, 2 \mathrm{H},{ }^{3} J=9.0 \mathrm{~Hz}, \mathrm{H}_{\text {pyr }}\right), 8.04(\mathrm{dd}$, $\left.1 \mathrm{H},{ }^{3} J_{\mathrm{Hpyr} 13-\mathrm{Hpyr} 12}={ }^{3} \mathrm{~J}_{\mathrm{Hpyr} 13-\mathrm{Hpyr14}}=9.0 \mathrm{~Hz}, \mathrm{H}_{\text {pyr13 }}\right), 7.66(\mathrm{~d}$, $\left.1 \mathrm{H},{ }^{3} J_{\mathrm{Hpy} 29-\mathrm{Hpy} 30}=7.9 \mathrm{~Hz}, \mathrm{H}_{\text {py29 }}\right), 7.19\left(\mathrm{dd}, 1 \mathrm{H}, \mathrm{H}_{\text {py30 }}\right), 7.05$ $\left(\mathrm{s}, 2 \mathrm{H}, \mathrm{H}_{\text {mes2 } 2}\right), 6.70\left(\mathrm{~d}, 1 \mathrm{H},{ }^{3} \mathrm{~J}_{\mathrm{Him} 2-\mathrm{Him} 3}=1.5 \mathrm{~Hz}, \mathrm{H}_{\mathrm{im} 2}\right), 6.66$ (s, 2H, $\mathrm{H}_{\text {pyr } 4}$ ), $6.52\left(\mathrm{~d}, 1 \mathrm{H}, \mathrm{H}_{\mathrm{im} 3}\right), 2.39$ (s, 3H, $\left.\mathrm{CH}_{3-\mathrm{mes} 25}\right), 2.35$ (s, 6H, $\left.\mathrm{CH}_{3-\mathrm{mes} 26}\right)$. APT $\left(100 \mathrm{MHz}, \mathrm{CDCl}_{3}\right): 151.84\left(\mathrm{CH}_{\mathrm{py} 27}\right)$, $150.85\left(\mathrm{CH}_{\mathrm{py} 31}\right), 148.37\left(\mathrm{C}_{\mathrm{im} 1}-\mathrm{Pd}\right), 139.42\left(\mathrm{C}_{\text {mes } 24}\right), 137.80$
$\left(\mathrm{CH}_{\text {py29 }}\right), 136.45,134.89\left(\mathrm{C}_{\text {mes21 }}\right), 132.39,132.28\left(\mathrm{C}_{\text {py28 }}\right)$, $131.33,130.95,130.15,129.48\left(\mathrm{CH}_{\text {mes23 }}\right), 129.11\left(\mathrm{C}_{\text {mes22 }}\right)$, 129.07 $\left(\mathrm{C}_{\text {mes } 22}\right), 128.33\left(\mathrm{CH}_{\text {pyr }}\right), 127.55,127.44\left(\mathrm{CH}_{\text {pyr }}\right)$, $126.42\left(\mathrm{CH}_{\text {pyr } 13}\right), 125.88\left(\mathrm{CH}_{\text {pyr }}\right), 125.80\left(\mathrm{CH}_{\text {pyr }}\right), 125.26$, $125.05\left(\mathrm{CH}_{\text {pyr }}\right), 124.73\left(\mathrm{CH}_{\text {py30 }}\right), 124.70\left(\mathrm{CH}_{\mathrm{im} 2}\right), 124.68$, $123.78\left(\mathrm{CH}_{\text {pyr } 6}\right), 121.42\left(\mathrm{CH}_{\mathrm{im} 3}\right), 54.80\left(\mathrm{CH}_{\text {pyr } 4}\right), 21.31$ $\left(\mathrm{CH}_{3 \text {-mes25 }}\right)$, $19.98\left(\mathrm{CH}_{3 \text {-mes26 }}\right)$. Elemental analysis calcd for $\mathrm{C}_{34} \mathrm{H}_{28} \mathrm{Br}_{2} \mathrm{ClN}_{3} \mathrm{Pd} \cdot 0.5 \mathrm{C}_{6} \mathrm{H}_{14}$ : C, 53.97; H, 4.28; N, 5.10. Found: C, 53.89; H, 4.15; N, 5.35. HRMS ESI-TOF-MS (positive mode): $[\mathrm{M}-\mathrm{Br}]^{+}$monoisotopic peak 700.0141; calcd 700.0211, $\varepsilon_{\mathrm{r}}: 1.0 \mathrm{ppm}$.

Synthesis of 2-rGO. A suspension of $180 \mathrm{mg}$ of $\mathrm{rGO}$ in 100 $\mathrm{mL}$ of $\mathrm{CH}_{2} \mathrm{Cl}_{2}$ was introduced in an ultrasounds bath for 30 min. Then, complex 2 ( $25 \mathrm{mg}, 0,032 \mathrm{mmol}$ ) was added to the mixture. The suspension was stirred at room temperature for $16 \mathrm{~h}$. The black solid was isolated by filtration and washed with $\mathrm{CH}_{2} \mathrm{Cl}_{2}(2 \times 15 \mathrm{~mL})$ affording the hybrid material as a black solid. The exact amount of supported complex was determined by ICP/MS analysis. The results accounted for a $5.5 \mathrm{wt} \%$ of complex 2 in the hybrid material 2-rGO.

Synthesis of 2-NPs. A Schlenk flask equipped with a stirring bar was charged with a solution of $2(30 \mathrm{mg}, 0.038 \mathrm{mmol})$ in toluene $(2 \mathrm{~mL})$ and $\mathrm{Cs}_{2} \mathrm{CO}_{3}(22 \mathrm{mg}, 0.067 \mathrm{mmol})$. A balloon of $\mathrm{H}_{2}$ ( $1 \mathrm{bar}$ ) was connected to the Schlenk, and the reaction mixture was stirred at $65{ }^{\circ} \mathrm{C}$ for $3 \mathrm{~h}$. After this time, the black solid formed was recovered by centrifugation, washed with toluene, and dried $(11 \mathrm{mg}) .2$-NPs were analyzed by TEM and XPS.

Synthesis of 2-rGO-NPs. A Schlenk flask equipped with a stirring bar was charged with 2-rGO $(30 \mathrm{mg}), \mathrm{Cs}_{2} \mathrm{CO}_{3}(17 \mathrm{mg}$, $0.052 \mathrm{mmol})$, and toluene $(2 \mathrm{~mL})$. A balloon of $\mathrm{H}_{2}$ (1 bar) was connected to the Schlenk, and the reaction mixture was stirred at $65{ }^{\circ} \mathrm{C}$ for $3 \mathrm{~h}$. After this time, 2-rGO-NPs were recovered by centrifugation, washed with toluene, and dried $(32 \mathrm{mg}) .2$ rGO-NPs were analyzed by TEM, XPS, TG, UV/vis, and Raman spectroscopy.

General Procedure for the Catalytic Hydrogenation of Alkynes. In a general catalytic experiment, a $10 \mathrm{~mL}$ Schlenk equipped with a stirring bar is charged with $0.3 \mathrm{mmol}$ of alkyne, base $\left(\mathrm{Cs}_{2} \mathrm{CO}_{3}, 10 \mathrm{~mol} \%\right)$ and catalyst, and $2 \mathrm{~mL}$ of dry toluene as the solvent. A balloon full of $\mathrm{H}_{2}$ is connected to the Schlenk. The Schlenk is then introduced in a preheated 65 ${ }^{\circ} \mathrm{C}$ oil bath. Yields and conversions were determined by GC or ${ }^{1} \mathrm{H}$ NMR analysis using anisole or 1,3,5-trimethoxybenzene as an internal standard.

\section{ASSOCIATED CONTENT}

\section{S Supporting Information}

The Supporting Information is available free of charge on the ACS Publications website at DOI: 10.1021/acsomega.8b02193.

General experimental details, characterization, crystallographic data, HRTEM images, XPS analysis, and hydrogenation reaction monitoring profiles. (PDF)

Crystallographic data of complex 2(CIF)

\section{AUTHOR INFORMATION}

\section{Corresponding Authors}

*E-mail: borjam@uji.es (P.B.).

*E-mail: jmata@uji.es. Phone: (+34) 964387516. Fax: (+34) 964387522 (J.A.M.). 


\section{ORCID}

Santiago Martín: 0000-0001-9193-3874

Pilar Borja: 0000-0001-6616-4399

Jose A. Mata: 0000-0001-9310-2783

\section{Present Address}

${ }^{\perp}$ School of Physical Science and Tecnology, Shanghaitech University, 393 Middle Huaxia Road, Pudong, Shanghai, 201210, China.

\section{Author Contributions}

The manuscript was written through contributions of all authors. All authors have given approval to the final version of the manuscript.

\section{Notes}

The authors declare no competing financial interest.

\section{ACKNOWLEDGMENTS}

The authors thank the financial support from MINECO (CTQ2015-69153-C2-2-R), Conselleria de Educación, Cultura y Deporte de la Generalitat Valenciana (GV/2018//107), and Universitat Jaume I (P1.1B2015-09). S.M. acknowledges DGA/fondos FEDER (construyendo Europa desde Aragón) for funding the research group Platón (E31_17R). P.B. thanks the Universitat Jaume I for a postdoctoral grant. D.V.E. thanks the MINECO for the FPU grant (FPU15/03011). The authors thank "Serveis Centrals d'Instrumentació Cientifica (SCIC)" of the Universitat Jaume I and Dr. G. Antorrena for the technical support in XPS studies.

\section{REFERENCES}

(1) Teschner, D.; Borsodi, J.; Wootsch, A.; Revay, Z.; Havecker, M.; Knop-Gericke, A.; Jackson, S. D.; Schlogl, R. The Roles of Subsurface Carbon and Hydrogen in Palladium-Catalyzed Alkyne Hydrogenation. Science 2008, 320, 86-89.

(2) Fortman, G. C.; Nolan, S. P. N-Heterocyclic Carbene (NHC) Ligands and Palladium in Homogeneous Cross-Coupling Catalysis: A Perfect Union. Chem. Soc. Rev. 2011, 40, 5151-5169.

(3) Beletskaya, I. P.; Cheprakov, A. V. The Heck Reaction as a Sharpening Stone of Palladium Catalysis. Chem. Rev. 2000, 100, 3009-3066.

(4) Johansson Seechurn, C. C. C.; Kitching, M. O.; Colacot, T. J.; Snieckus, V. Palladium-Catalyzed Cross-Coupling: A Historical Contextual Perspective to the 2010 Nobel Prize. Angew. Chem., Int. Ed. 2012, 51, 5062-5085.

(5) Kantchev, E. A. B.; O’Brien, C. J.; Organ, M. G. Palladium Complexes of N-Heterocyclic Carbenes as Catalysts for CrossCoupling Reactions-A Synthetic Chemist's Perspective. Angew. Chem., Int. Ed. 2007, 46, 2768-2813.

(6) Sprengers, J. W.; Wassenaar, J.; Clement, N. D.; Cavell, K. J.; Elsevier, C. J. Palladium-(N-Heterocyclic Carbene) Hydrogenation Catalysts. Angew. Chem., Int. Ed. 2005, 44, 2026-2029.

(7) Torborg, C.; Beller, M. Recent Applications of PalladiumCatalyzed Coupling Reactions in the Pharmaceutical, Agrochemical, and Fine Chemical Industries. Adv. Synth. Catal. 2009, 351, 30273043.

(8) Zapf, A.; Beller, M. Fine Chemical Synthesis with Homogeneous Palladium Catalysts: Examples, Status and Trends. Top. Catal. 2002, 19, 101-109.

(9) Mata, J. A.; Poyatos, M. Recent Developments in the Applications of Palladium Complexes Bearing N-Heterocyclic Carbene Ligands. Curr. Org. Chem. 2011, 15, 3309-3324.

(10) Chun, Y. S.; Shin, J. Y.; Song, C. E.; Lee, S.-g. Palladium Nanoparticles Supported onto Ionic Carbon Nanotubes as Robust Recyclable Catalysts in an Ionic Liquid. Chem. Commun. 2008, 7345, 942-944.
(11) Ott, L. S.; Finke, R. G. Transition-Metal Nanocluster Stabilization for Catalysis: A Critical Review of Ranking Methods and Putative Stabilizers. Coord. Chem. Rev. 2007, 251, 1075-1100.

(12) Astruc, D.; Lu, F.; Aranzaes, J. R. Nanoparticles as Recyclable Catalysts: The Frontier between Homogeneous and Heterogeneous Catalysis. Angew. Chem., Int. Ed. 2005, 44, 7852-7872.

(13) Aiken, J. D.; Finke, R. G. A Review of Modern Transition-Metal Nanoclusters: Their Synthesis, Characterization, and Applications in Catalysis. J. Mol. Catal. A: Chem. 1999, 145, 1-44.

(14) Reetz, M. T.; de Vries, J. G. Ligand-Free Heck Reactions Using Low Pd-Loading. Chem. Commun. 2004, 14, 1559-1563.

(15) Górna, M.; Szulmanowicz, M. S.; Gniewek, A.; Tylus, W.; Trzeciak, A. M. Recyclable $\mathrm{Pd}(0)-\mathrm{Pd}(\mathrm{II})$ composites formed from $\mathrm{Pd}$ (II) dimers with NHC ligands under Suzuki-Miyaura conditions. J. Organomet. Chem. 2015, 785, 92-99.

(16) Ferry, A.; Schaepe, K.; Tegeder, P.; Richter, C.; Chepiga, K. M.; Ravoo, B. J.; Glorius, F. Negatively Charged N-Heterocyclic CarbeneStabilized Pd and $\mathrm{Au}$ Nanoparticles and Efficient Catalysis in Water. ACS Catal. 2015, 5, 5414-5420.

(17) Richter, C.; Schaepe, K.; Glorius, F.; Ravoo, B. J. Tailor-Made $\mathrm{N}-H e t e r o c y c l i c$ Carbenes for Nanoparticle Stabilization. Chem. Commun. 2014, 50, 3204-3207.

(18) Planellas, M.; Pleixats, R.; Shafir, A. Palladium Nanoparticles in Suzuki Cross-Couplings: Tapping into the Potential of TrisImidazolium Salts for Nanoparticle Stabilization. Adv. Synth. Catal. 2012, 354, 651-662.

(19) Putta, C.; Sharavath, V.; Sarkar, S.; Ghosh, S. Palladium nanoparticles on $\beta$-cyclodextrin functionalised graphene nanosheets: a supramolecular based heterogeneous catalyst for C-C coupling reactions under green reaction conditions. RSC $A d v$. 2015, 5, $6652-6660$.

(20) Luska, K. L.; Moores, A. Improved Stability and Catalytic Activity of Palladium Nanoparticle Catalysts Using PhosphineFunctionalized Imidazolium Ionic Liquids. Adv. Synth. Catal. 2011, 353, 3167-3177.

(21) Pontes da Costa, A.; Nunes, D. R.; Tharaud, M.; Oble, J.; Poli, G.; Rieger, J. Palladium(0) Nanoparticles Embedded in Core-shell Nanogels as Recoverable Catalysts for the Mizoroki-Heck Reaction. Chem CatChem 2017, 9, 2167-2175.

(22) Narayanan, R.; El-Sayed, M. A. Effect of Catalysis on the Stability of Metallic Nanoparticles: Suzuki Reaction Catalyzed by PVP-Palladium Nanoparticles. J. Am. Chem. Soc. 2003, 125, 83408347.

(23) Sankar, M.; Dimitratos, N.; Miedziak, P. J.; Wells, P. P.; Kiely, C. J.; Hutchings, G. J. Designing Bimetallic Catalysts for a Green and Sustainable Future. Chem. Soc. Rev. 2012, 41, 8099-8139.

(24) White, R. J.; Luque, R.; Budarin, V. L.; Clark, J. H.; Macquarrie, D. J. Supported Metal Nanoparticles on Porous Materials. Methods and Applications. Chem. Soc. Rev. 2009, 38, 481-494.

(25) Gallon, B. J.; Kojima, R. W.; Kaner, R. B.; Diaconescu, P. L. Palladium Nanoparticles Supported on Polyaniline Nanofibers as a Semi-Heterogeneous Catalyst in Water. Angew. Chem., Int. Ed. 2007, $46,7251-7254$.

(26) Wildgoose, G. G.; Banks, C. E.; Compton, R. G. Metal Nanoparticles and Related Materials Supported on Carbon Nanotubes: Methods and Applications. Small 2006, 2, 182-193.

(27) Pachón, L. D.; Rothenberg, G. Transition-Metal Nanoparticles: Synthesis, Stability and the Leaching Issue. Appl. Organomet. Chem. 2008, 22, 288-299.

(28) Shi, X.; Cai, C. Imidazolium-based ionic liquid functionalized reduced graphene oxide supported palladium as a reusable catalyst for Suzuki-Miyaura reactions. New J. Chem. 2018, 42, 2364-2367.

(29) Scheuermann, G. M.; Rumi, L.; Steurer, P.; Bannwarth, W.; Mülhaupt, R. Palladium Nanoparticles on Graphite Oxide and Its Functionalized Graphene Derivatives as Highly Active Catalysts for the Suzuki-Miyaura Coupling Reaction. J. Am. Chem. Soc. 2009, 131, $8262-8270$. 
(30) Marion, N.; Nolan, S. P. Well-Defined N-Heterocyclic Carbenes-Palladium(II) Precatalysts for Cross-Coupling Reactions. Acc. Chem. Res. 2008, 41, 1440-1449.

(31) Meiries, S.; Le Duc, G.; Chartoire, A.; Collado, A.; Speck, K.; Arachchige, K. S. A.; Slawin, A. M. Z.; Nolan, S. P. Large yet Flexible N-Heterocyclic Carbene Ligands for Palladium Catalysis. Chem.Eur. J. 2013, 19, 17358-17368.

(32) Fantasia, S.; Egbert, J. D.; Jurčík, V.; Cazin, C. S. J.; Jacobsen, H.; Cavallo, L.; Heinekey, D. M.; Nolan, S. P. Activation of Hydrogen by Palladium(0): Formation of the Mononuclear Dihydride Complextrans-[Pd(H)2(IPr) (PCy3)]. Angew. Chem., Int. Ed. 2009, 48, 51825186.

(33) Valente, C.; Pompeo, M.; Sayah, M.; Organ, M. G. CarbonHeteroatom Coupling Using Pd-PEPPSI Complexes. Org. Process Res. Dev. 2014, 18, 180-190.

(34) Sabater, S.; Mata, J. A.; Peris, E. Catalyst Enhancement and Recyclability by Immobilization of Metal Complexes onto Graphene Surface by Noncovalent Interactions. ACS Catal. 2014, 4, 20382047.

(35) Sabater, S.; Mata, J. A.; Peris, E. Immobilization of PyreneTagged Palladium and Ruthenium Complexes onto Reduced Graphene Oxide: An Efficient and Highly Recyclable Catalyst for Hydrodefluorination. Organometallics 2015, 34, 1186-1190.

(36) Ventura-Espinosa, D.; Marzá-Beltrán, A.; Mata, J. A. Catalytic Hydrogen Production by Ruthenium Complexes from the Conversion of Primary Amines to Nitriles: Potential Application as a Liquid Organic Hydrogen Carrier. Chem.-Eur. J. 2016, 22, 17758-17766.

(37) Ventura-Espinosa, D.; Vicent, C.; Baya, M.; Mata, J. A. Ruthenium Molecular Complexes Immobilized on Graphene as Active Catalysts for the Synthesis of Carboxylic Acids from Alcohol Dehydrogenation. Catal. Sci. Technol. 2016, 6, 8024-8035.

(38) Ventura-Espinosa, D.; Carretero-Cerdán, A.; Baya, M.; García, H.; Mata, J. A. Catalytic Dehydrogenative Coupling of Hydrosilanes with Alcohols for the Production of Hydrogen On-Demand: Application of a Silane/Alcohol Pair as a Liquid Organic Hydrogen Carrier. Chem.-Eur. J. 2017, 23, 10815-10821.

(39) Ventura-Espinosa, D.; Sabater, S.; Carretero-Cerdán, A.; Baya, M.; Mata, J. A. High Production of Hydrogen on Demand from Silanes Catalyzed by Iridium Complexes as a Versatile Hydrogen Storage System. ACS Catal. 2018, 8, 2558-2566.

(40) Ventura-Espinosa, D.; Sabater, S.; Mata, J. A. Enhancement of Gold Catalytic Activity and Stability by Immobilization on the Surface of Graphene. J. Catal. 2017, 352, 498-504.

(41) Ruiz-Botella, S.; Peris, E. Unveiling the Importance of $\pi$ Stacking in Borrowing-Hydrogen Processes Catalysed by Iridium Complexes with Pyrene Tags. Chem.-Eur. J. 2015, 21, 1526315271 .

(42) Lara, P.; Rivada-Wheelaghan, O.; Conejero, S.; Poteau, R.; Philippot, K.; Chaudret, B. Ruthenium Nanoparticles Stabilized by NHeterocyclic Carbenes: Ligand Location and Influence on Reactivity. Angew. Chem., Int. Ed. 2011, 50, 12080-12084.

(43) Dassenoy, F.; Philippot, K.; Ould Ely, T.; Amiens, C.; Lecante, P.; Snoeck, E.; Mosset, A.; Casanove, M.-J.; Chaudret, B. Platinum Nanoparticles Stabilized by $\mathrm{CO}$ and Octanethiol Ligands or Polymers: FT-IR, NMR, HREM and WAXS Studies. New J. Chem. 1998, 22, 703-712.

(44) Pan, C.; Dassenoy, F.; Casanove, M.-J.; Philippot, K.; Amiens, C.; Lecante, P.; Mosset, A.; Chaudret, B. A New Synthetic Method toward Bimetallic Ruthenium Platinum Nanoparticles; Composition Induced Structural Changes. J. Phys. Chem. B 1999, 103, 1009810101.

(45) Ely, T. O.; Pan, C.; Amiens, C.; Chaudret, B.; Dassenoy, F.; Lecante, P.; Casanove, M.-J.; Mosset, A.; Respaud, M.; Broto, J.-M. Nanoscale Bimetallic CoxPt1-xParticles Dispersed in Poly(vinylpyrrolidone): Synthesis from Organometallic Precursors and Characterization. J. Phys. Chem. B 2000, 104, 695-702.

(46) Vidoni, O.; Philippot, K.; Amiens, C.; Chaudret, B.; Balmes, O.; Malm, J.-O.; Bovin, J.-O.; Senocq, F.; Casanove, M.-J. Novel,
Spongelike Ruthenium Particles of Controllable Size Stabilized Only by Organic Solvents. Angew. Chem., Int. Ed. 1999, 38, 3736-3738.

(47) Gonzalez-Galvez, D.; Lara, P.; Rivada-Wheelaghan, O.; Conejero, S.; Chaudret, B.; Philippot, K.; van Leeuwen, P. W. N. M. NHC-Stabilized Ruthenium Nanoparticles as New Catalysts for the Hydrogenation of Aromatics. Catal. Sci. Technol. 2013, 3, 99-105.

(48) Asensio, J. M.; Tricard, S.; Coppel, Y.; Andrés, R.; Chaudret, B.; de Jesús, E. Knight Shift in13C NMR Resonances Confirms the Coordination of N-Heterocyclic Carbene Ligands to Water-Soluble Palladium Nanoparticles. Angew. Chem., Int. Ed. 2017, 56, 865-869.

(49) Asensio, J. M.; Tricard, S.; Coppel, Y.; Andrés, R.; Chaudret, B.; de Jesús, E. Synthesis of Water-Soluble Palladium Nanoparticles Stabilized by Sulfonated N-Heterocyclic Carbenes. Chem.-Eur. J. 2017, 23, 13435-13444.

(50) Baquero, E. A.; Tricard, S.; Flores, J. C.; de Jesús, E.; Chaudret, B. Highly Stable Water-Soluble Platinum Nanoparticles Stabilized by Hydrophilic N-Heterocyclic Carbenes. Angew. Chem., Int. Ed. 2014, 53, 13220-13224.

(51) Baquero, E. A.; Tricard, S.; Coppel, Y.; Flores, J. C.; Chaudret, B.; de Jesús, E. Water-Soluble Platinum Nanoparticles Stabilized by Sulfonated N-Heterocyclic Carbenes: Influence of the Synthetic Approach. Dalton Trans. 2018, 47, 4093-4104.

(52) Canseco-Gonzalez, D.; Gniewek, A.; Szulmanowicz, M.; Müller-Bunz, H.; Trzeciak, A. M.; Albrecht, M. PEPPSI-Type Palladium Complexes Containing Basic 1,2,3-Triazolylidene Ligands and Their Role in Suzuki-Miyaura Catalysis. Chem.-Eur. J. 2012, 18, 6055-6062.

(53) Torres-Mendieta, R.; Ventura-Espinosa, D.; Sabater, S.; Lancis, J.; Mínguez-Vega, G.; Mata, J. A. In Situ Decoration of Graphene Sheets with Gold Nanoparticles Synthetized by Pulsed Laser Ablation in Liquids. Sci. Rep. 2016, 6, 30478.

(54) Navalon, S.; Dhakshinamoorthy, A.; Alvaro, M.; Garcia, H. Metal Nanoparticles Supported on Two-Dimensional Graphenes as Heterogeneous Catalysts. Coord. Chem. Rev. 2016, 312, 99-148.

(55) Jeon, E. K.; Seo, E.; Lee, E.; Lee, W.; Um, M.-K.; Kim, B.-S. Mussel-Inspired Green Synthesis of Silver Nanoparticles on Graphene Oxide Nanosheets for Enhanced Catalytic Applications. Chem. Commun. 2013, 49, 3392-3394.

(56) Johnson, C.; Albrecht, M. Z-Selective alkyne semi-hydrogenation catalysed by piano-stool $\mathrm{N}$-heterocyclic carbene iron complexes. Catal. Sci. Technol. 2018, 8, 2779-2783.

(57) Conley, M. P.; Drost, R. M.; Baffert, M.; Gajan, D.; Elsevier, C.; Franks, W. T.; Oschkinat, H.; Veyre, L.; Zagdoun, A.; Rossini, A.; et al. A Well-Defined Pd Hybrid Material for theZ-Selective Semihydrogenation of Alkynes Characterized at the Molecular Level by DNP SENS. Chem.-Eur. J. 2013, 19, 12234-12238.

(58) Sluijter, S. N.; Warsink, S.; Lutz, M.; Elsevier, C. J. Synthesis of Palladium(0) and -(Ii) Complexes with Chelating Bis(N-Heterocyclic Carbene) Ligands and Their Application in Semihydrogenation. Dalton Trans. 2013, 42, 7365-7372.

(59) Drost, R. M.; Bouwens, T.; van Leest, N. P.; de Bruin, B.; Elsevier, C. J. Convenient Transfer Semihydrogenation Methodology for Alkynes Using a PdII-NHC Precatalyst. ACS Catal. 2014, 4, $1349-1357$

(60) Hauwert, P.; Boerleider, R.; Warsink, S.; Weigand, J. J.; Elsevier, C. J. Mechanism of Pd(NHC)-Catalyzed Transfer Hydrogenation of Alkynes. J. Am. Chem. Soc. 2010, 132, 16900-16910.

(61) Crabtree, R. H. Resolving Heterogeneity Problems and Impurity Artifacts in Operationally Homogeneous Transition Metal Catalysts. Chem. Rev. 2012, 112, 1536-1554.

(62) Drost, R. M.; Rosar, V.; Marta, S. D.; Lutz, M.; Demitri, N.; Milani, B.; de Bruin, B.; Elsevier, C. J. Pd-CatalyzedZ-Selective Semihydrogenation of Alkynes: Determining the Type of Active Species. ChemCatChem 2015, 7, 2095-2107.

(63) Klingelhöfer, S.; Heitz, W.; Greiner, A.; Oestreich, S.; Förster, S.; Antonietti, M. Preparation of Palladium Colloids in Block Copolymer Micelles and Their Use for the Catalysis of the Heck Reaction. J. Am. Chem. Soc. 1997, 119, 10116-10120. 
(64) Foley, P.; DiCosimo, R.; Whitesides, G. M. Mechanism of Thermal Decomposition of Dineopentylbis(Triethylphosphine)Platinum(II): Formation of Bis(Triethylphosphine)-3,3-Dimethylplatinacyclobutane. J. Am. Chem. Soc. 1980, 102, 6713-6725.

(65) Weck, M.; Jones, C. W. Mizoroki-Heck Coupling Using Immobilized Molecular Precatalysts: Leaching Active Species from Pd Pincers, Entrapped Pd Salts, and Pd NHC Complexes. Inorg. Chem. 2007, 46, 1865-1875.

(66) Richardson, J. M.; Jones, C. W. Poly(4-vinylpyridine) and Quadrapure TU as Selective Poisons for Soluble Catalytic Species in Palladium-Catalyzed Coupling Reactions - Application to Leaching from Polymer-Entrapped Palladium. Adv. Synth. Catal. 2006, 348, $1207-1216$

(67) Phan, N. T. S.; Van Der Sluys, M.; Jones, C. W. On the Nature of the Active Species in Palladium Catalyzed Mizoroki-Heck and Suzuki-Miyaura Couplings - Homogeneous or Heterogeneous Catalysis, A Critical Review. Adv. Synth. Catal. 2006, 348, 609-679.

(68) Samantaray, M. K.; Alauzun, J.; Gajan, D.; Kavitake, S.; Mehdi, A.; Veyre, L.; Lelli, M.; Lesage, A.; Emsley, L.; Copéret, C.; et al. Evidence for Metal-Surface Interactions and Their Role in Stabilizing Well-Defined Immobilized Ru-NHC Alkene Metathesis Catalysts. J. Am. Chem. Soc. 2013, 135, 3193-3199.

(69) Maishal, T. K.; Alauzun, J.; Basset, J.-M.; Copéret, C.; Corriu, R. J. P.; Jeanneau, E.; Mehdi, A.; Reyé, C.; Veyre, L.; Thieuleux, C. A Tailored Organometallic-Inorganic Hybrid Mesostructured Material: A Route to a Well-Defined, Active, and Reusable Heterogeneous Iridium-NHC Catalyst for $\mathrm{H} / \mathrm{D}$ Exchange. Angew. Chem., Int. Ed. 2008, 47, 8654-8656.

(70) Conley, M. P.; Copéret, C. State of the Art and Perspectives in the "Molecular Approach" Towards Well-Defined Heterogeneous Catalysts. Top. Catal. 2014, 57, 843-851.

(71) Copéret, C.; Comas-Vives, A.; Conley, M. P.; Estes, D. P.; Fedorov, A.; Mougel, V.; Nagae, H.; Núñez-Zarur, F.; Zhizhko, P. A. Surface Organometallic and Coordination Chemistry toward SingleSite Heterogeneous Catalysts: Strategies, Methods, Structures, and Activities. Chem. Rev. 2016, 116, 323-421.

(72) Dupont, J.; Scholten, J. D. On the Structural and Surface Properties of Transition-Metal Nanoparticles in Ionic Liquids. Chem. Soc. Rev. 2010, 39, 1780-1804.

(73) Migowski, P.; Dupont, J. Catalytic Applications of Metal Nanoparticles in Imidazolium Ionic Liquids. Chem.-Eur. J. 2007, 13, $32-39$.

(74) Scholten, J. D.; Leal, B. C.; Dupont, J. Transition Metal Nanoparticle Catalysis in Ionic Liquids. ACS Catal. 2012, 2, 184200.

(75) Cassol, C. C.; Umpierre, A. P.; Machado, G.; Wolke, S. I.; Dupont, J. The Role of Pd Nanoparticles in Ionic Liquid in the Heck Reaction. J. Am. Chem. Soc. 2005, 127, 3298-3299.

(76) Umpierre, A. P.; Machado, G.; Fecher, G. H.; Morais, J.; Dupont, J. Selective Hydrogenation of 1,3-Butadiene to 1-Butene by $\operatorname{Pd}(0)$ Nanoparticles Embedded in Imidazolium Ionic Liquids. Adv. Synth. Catal. 2005, 347, 1404-1412.

(77) Pan, C.; Pelzer, K.; Philippot, K.; Chaudret, B.; Dassenoy, F.; Lecante, P.; Casanove, M.-J. Ligand-Stabilized Ruthenium Nanoparticles: Synthesis, Organization, and Dynamics. J. Am. Chem. Soc. 2001, 123, 7584-7593.

(78) Eremin, D. B.; Ananikov, V. P. Understanding active species in catalytic transformations: From molecular catalysis to nanoparticles, leaching, "Cocktails" of catalysts and dynamic systems. Coord. Chem. Rev. 2017, 346, 2-19.

(79) Astakhov, A. V.; Khazipov, O. V.; Chernenko, A. Y.; Pasyukov, D. V.; Kashin, A. S.; Gordeev, E. G.; Khrustalev, V. N.; Chernyshev, V. M.; Ananikov, V. P. A New Mode of Operation of Pd-NHC Systems Studied in a Catalytic Mizoroki-Heck Reaction. Organometallics 2017, 36, 1981-1992.

(80) Khazipov, O. V.; Shevchenko, M. A.; Chernenko, A. Y.; Astakhov, A. V.; Pasyukov, D. V.; Eremin, D. B.; Zubavichus, Y. V.; Khrustalev, V. N.; Chernyshev, V. M.; Ananikov, V. P. Fast and Slow
Release of Catalytically Active Species in Metal/NHC Systems Induced by Aliphatic Amines. Organometallics 2018, 37, 1483-1492. (81) Yakukhnov, S. A.; Pentsak, E. O.; Galkin, K. I.; Mironenko, R. M.; Drozdov, V. A.; Likholobov, V. A.; Ananikov, V. P. Rapid "Mixand-Stir" Preparation of Well-Defined Palladium on Carbon Catalysts for Efficient Practical Use. ChemCatChem 2018, 10, 1869-1873.

(82) Wang, X.; Choi, S.-I.; Roling, L. T.; Luo, M.; Ma, C.; Zhang, L.; Chi, M.; Liu, J.; Xie, Z.; Herron, J. A.; et al. Palladium-platinum Core-Shell Icosahedra with Substantially Enhanced Activity and Durability towards Oxygen Reduction. Nat. Commun. 2015, 6, 7594.

(83) Li, C.; Sato, R.; Kanehara, M.; Zeng, H.; Bando, Y.; Teranishi, T. Controllable Polyol Synthesis of Uniform Palladium Icosahedra: Effect of Twinned Structure on Deformation of Crystalline Lattices. Angew. Chem., Int. Ed. 2009, 48, 6883-6887.

(84) Xing, X.; Hermann, A.; Kuang, X.; Ju, M.; Lu, C.; Jin, Y.; Xia, X.; Maroulis, G. Insights into the Geometries, Electronic and Magnetic Properties of Neutral and Charged Palladium Clusters. Sci. Rep. 2016, 6, 19656. 